\title{
As Ilhas e a expansão da cultura e tecnologia da cana-de-açúcar no Atlântico nos séculos XV a XIX
}

\author{
Alberto Vieira \\ (-) Centro de Estudos de História do Atlântico - CEHA. Funchal [Madeira], Portugal. <alb.alberto@gmail.com>.
}

Artigo originalmente publicado em 2007, pela Revista Labor \& Engenho, ISSN:1891-1152, em papel.

\section{Resumo}

No século XV, A Madeira surge como a primeira experiência de ocupação portuguesa em que se ensaiaram produtos, técnicas e estruturas institucionais, que foram, depois, utilizados em larga escala noutras ilhas, litoral africano e americano. O arquipélago madeirense foi o centro de irradiação dos sustentáculos da nova sociedade e economia do mundo atlântico: primeiro os Açores, depois os demais arquipélagos e regiões costeiras onde os portugueses aportaram. A Madeira marcou a História da Cana-de-açúcar entre os séculos XV e XX. Todavia, esta cultura não se manteve como uma constante da história da ilha, notando-se um hiato no século XVIII. A cultura da cana-de-açúcar se expandiu, tornando-se importante fator de animação da agricultura e da indústria madeirense. A Madeira esteve na linha da frente das inovações tecnológicas. Nos séculos XV e XVI acresce a função de distribuição da cultura e técnica em todo o espaço atlântico. Para finais do século XIX e princípios do seguinte, ficaria reservado papel pioneiro no ensaio de algumas técnicas e sistemas de fabrico de açúcar e aguardente que revolucionaram todo o processo industrial.

\section{Palavras-chave}

Tecnologia do açúcar, história do açúcar, cultura do açúcar

\section{The Islands and the expansion of the culture and technology from sugar cane in the Atlantic in the centuries XV to XIX}

\begin{abstract}
In the fifteenth century, Madeira emerges as the first experience of Portuguese occupation in which they rehearsed products, techniques and institutional structures, all of them used extensively in other islands, African and American coast. Madeira archipelago was the center of irradiation of the new society and economy in the Atlantic world: Azores first, then the other islands and coastal regions where the Portuguese landed. Madeira marked the history of sugar cane, between the fifteenth and twentieth centuries. However, this culture was not maintained as a constant in the history of the island, there was a gap in the eighteenth century. The cultivation of sugar cane has expanded, becoming an important factor for the agriculture and industry in Madeira. The Island has been at the frontline of technological innovations. In the late nineteenth and early twentieth century, it would be reserved pioneering role in the trial of some techniques and systems for manufacturing sugar and spirit that revolutionized the entire process.
\end{abstract}

\section{Keywords}

Sugar technology, history of sugar, sugar culture. 
“... são huns principais partos e invenções do engenho humano" [Pe. António Vieira, Sermões, Porto, 1908, vol. 11, p.282]

A Madeira surge, nos alvores do século $X V$, como a primeira experiência de ocupação em que se ensaiaram produtos, técnicas e estruturas institucionais. Tudo isto foi, depois, utilizado, em larga escala, noutras ilhas, litoral africano e americano. $O$ arquipélago madeirense foi o centro de irradiação dos sustentáculos da nova sociedade e economia do mundo atlântico: primeiro os Açores, depois os demais arquipélagos e regiões costeiras onde os portugueses aportaram. Daqui resultou para a Madeira o papel fundamental de difusão das culturas existentes na Europa e que tinham valor mercantil ou pela necessidade para assegurar a subsistência. Depois,com a revelação de novos espaços do Atlântico e Índico tivemos o retorno de outras culturas e produtos que vieram enriquecer o cardápio europeu.

Foi no Atlântico que a cultura atingiu a plena afirmação econômica, assumindo posição dominante nas trocas. Fernand Braudel define de modo claro a forma de intervenção e as mudanças provocadas pelo açúcar:

"Devastadora do antigo equilíbrio, a cana é tanto mais perigosa quanto é apoiada por um capitalismo poderoso, que, no século XVI, Provem tanto de Itália, como de Lisboa ou de Antuérpia, e ao qual ninguém consegue resistir" ${ }^{\text {. }}$.

Vitorino Magalhães Godinho acrescenta que "a gênese do mundo atlântico está pois, em grande parte, ligada àquilo a que Fernand Braudel chama muito apropriadamente dinâmica do açúcar."2

No traçado das rotas oceânicas situava-se o Mediterrâneo Atlântico com um papel primordial na manutenção e apoio à navegação atlântica. As ilhas da Madeira e Canárias surgiram nos séculos XV e XVI como entrepostos do comércio no litoral africano, americano e asiático. Os portos principais da Madeira, Gran Canaria, La Gomera, Hierro, Tenerife e Lanzarote animaram-se de forma diversa com o apoio à navegação e comércio nas rotas da ida, enquanto nos Açores, com as ilhas de Flores, Corvo, Terceira, e S. Miguel, foram a escala necessária e fundamental da rota de retorno. A posição demarcada do Mediterrâneo Atlântico no comércio e navegação atlântica fez com que as coroas peninsulares investissem aí todas as tarefas de apoio, defesa e controle do trato comercial. As ilhas foram os bastiões avançados, suportes e os símbolos da hegemonia peninsular no Atlântico. A disputa pela riqueza em movimento no oceano fazia-se na área definida por elas e atraiu piratas e corsários ingleses, franceses e holandeses, ávidos das riquezas em circulação. Uma das maiores preocupações das coroas peninsulares foi a defesa das embarcações das investidas dos corsários europeus. A área definida pela Península Ibérica, Canárias e Açores foi o principal foco de intervenção do corso europeu sobre os navios que transportavam açúcar ou pastel ao velho continente.

\footnotetext{
${ }^{1}$ O Mediterrâneo e o Mundo Mediterrânico, Lisboa, 1983 [1ª edição em 1966], p.178

${ }^{2}$ Mito e Mercadoria Utopia e Prática de Navegar. Séculos XIII-XVIII, Lisboa, 1990, p.478
} 
Podemos dizer que a história do açúcar nas ilhas define-se por dois momentos distintos. Os séculos XV a XVII em que as mesmas assumem um papel na expansão da cultura e definição do mercado atlântico-europeu para o açúcar. Depois de um hiato de quase duas centúrias, a cultura retorna aos campos insulares por condições diversas e em posição distinta. Assim, a segunda metade da centúria oitocentista foi marcada pela dominância dos canaviais em algumas das ilhas, assumindo na Madeira um protagonismo evidente. Apenas os Açores haviam abandonado definitivamente a cana sacarina, apostando na ilha de São Miguel em outro recurso, a beterraba, para produzir açúcar e álcool.

No processo de transmigração para o Ocidente, as ilhas mediterrânicas de Chipre e Sicília foram destacados entrepostos de alargamento da cultura ao mundo ocidental e que, segundo a tradição, as primeiras mudas de cana teriam chegado à Madeira a partir da Sicília. Depois, foi a expansão no Atlântico com as ilhas que serviram de novo como anteparo. Não fica por aqui o protagonismo das ilhas, pois aos insulares, para além da dimensão divulgadora da cultura, foi-lhes ainda atribuída a tarefa de inventar novas formas e técnicas de transformação do produto adequadas à dimensão da área cultivada. Acresce ainda o papel recente da Madeira na adaptação da tecnologia, usada na Europa para a transformação da beterraba em açúcar e no fabrico do açúcar de cana sacarina.

O açúcar é, entre todos os produtos com valor comercial, o que foi alvo de maiores inovações tecnológicas para o fabrico, por força da pressão do mercado e do ciclo vegetativo da cultura. No caso do vinho, a tecnologia pouco ou nada mudou desde o tempo dos romanos. Várias condicionantes favoreceram a necessidade de permanente atualização da tecnologia no fabrico do açúcar, situação que se tornou mais clara no século XVIII com a concorrência da beterraba. Mesmo assim, ainda hoje persiste o fabrico sem atualização tecnológica em alguns recantos do mundo, como China, Índia ou Brasil, onde a tecnologia da revolução industrial ainda não entrou.

O fabrico do açúcar está limitado pela situação e ciclo vegetativo da planta. A cana sacarina tem um período útil de vida em que a percentagem de sacarose era mais elevada ${ }^{3}$. A cana estava pronta para ser colhida e a partir dali, um dia que passasse, era uma perda para o produto. Acresce que, depois de cortada, tem pouco mais de 48 horas para ser moída e cozida, pois caso contrário, começa a perder sacarose e inicia-se o processo de fermentação. Dai resulta a necessidade de acelerar o processo de fabrico do açúcar através de constantes inovações tecnológicas que cobrem o processo de corte, esmagamento e cozedura ${ }^{4}$. A isto se junta o aumento da mão-de-obra, que se faz à custa de escravos africanos. A cana-de-açúcar não está na origem da escravidão africana, mas no processo de afirmação, a partir da Madeira. Enquanto a cultura se fazia em pequenas parcelas, a maior parte das questões não se colocavam, mas quando se avançou para uma produção em larga escala, houve necessidade de encontrar soluções capazes de resolver a situação, através da aceleração do processo de moenda e fabrico. A viragem aconteceu a partir de meados do século XV na Madeira e deve ter implicado mudanças radicais

\footnotetext{
${ }^{3}$ Cf. J. de Laguarrique de Survilliers, Manuel de Sucrerie de Cannes, Paris, 1932, pp. 29.

${ }^{4}$ Cf. Nilo Cairo, O Livro da Canna de Assucar, Curitiba, 1924, pp. 85-86, 109; A. Bernard, A Evolução das Moendas de Canas, Brasil Açucareiro, XXXVIII, 2, 1951, pp. 73, 76.
} 
na tecnologia usada e na afirmação da escravatura dos indígenas das Canárias e negros da Costa da Guiné. É por isso que se assinala, a partir da Madeira, importantes inovações tecnológicas no sistema de moenda da cana com a generalização do sistema de cilindros.

A história tecnológica evidencia que a expansão européia condicionou a divulgação de técnicas existentes e permitiu a invenção de novas, que contribuíram para revolucionar a economia mundial. Os homens que circularam no espaço atlântico foram portadores de uma cultura tecnológica, que divulgaram nos quatro cantos e adaptaram às condições dos espaços de povoamento agrícola. Aos madeirenses foi atribuída uma missão especial nos primórdios do processo.

Na Madeira, um dos aspectos mais evidentes da revolução tecnológica iniciada no século XV, refere-se à capacidade do europeu em adaptar as técnicas de transformação conhecidas às circunstâncias e às exigências de culturas e produtos tão exigentes como a cana e o açúcar. O tributo foi evidente. Ao vinho, foi-se buscar a prensa; ao azeite e aos cereais, a mó de pedra. Por outro lado, estamos perante uma permuta constante de processos tecnológicos e formas de aproveitamento das diversas fontes de energia. A tração animal, a força motriz do vento e da água foram usadas em simultâneo com os cereais e cana sacarina.

As mudanças ocorridas a partir de finais do século XVIII, com a plena afirmação da máquina a vapor, conduziram a uma transformação radical do complexo açucareiro, que assume a dimensão espacial de uma fábrica, onde todas as operações se executam em série apenas numa planta. A revolução industrial nos legou a fábrica, fez aparecer o laboratório, uma peça chave no fabrico do açúcar, e obrigou a uma especialização dos técnicos envolvidos. O mestre de engenho dá lugar ao engenheiro químico. Paulatinamente, o processo de transformação da cana sacarina em açúcar retirou espaço à presença de mão-de-obra escrava, substituindo-a por imigrantes europeus, indianos e chineses.

A tecnologia da moenda e fabrico do açúcar é um tema de grande interesse no debate historiográfico sobre o açúcar e aguardente. Aliás, na segunda metade do século $X X$, foi um dos temas que mais preocupou os investigadores, motivando aceso debate, nomeadamente sobre a questão do uso da tecnologia dos cilindros. Em 2000, organizou-se um primeiro debate sobre o tema, no sentido de fazer o ponto da situação ${ }^{5}$.

A história da tecnologia do açúcar tem sido polêmica desde o início e não tem sido fácil vencer os complexos nacionalistas na busca da resposta certa para as inúmeras dúvidas que subsistem sobre as inovações, 0 momento da sua concretização e a paternidade. Contribuir para o debate, que ainda está longe de terminar, é o objetivo que nos move com o presente estudo, o qual procura realçar o contributo madeirense ao progresso da tecnologia açucareira.

Na história da tecnologia açucareira, o século XIX marca um momento decisivo na transformação do processo de fabrico do engenho, que passa a depender de

\footnotetext{
${ }^{5}$ História e Tecnologia do Açúcar, Funchal, 2000.
} 
tecnologias importadas, nomeadamente, da Inglaterra e França. Sucede que esta inovação tecnológica, porque implicará investimentos elevados, só se tornou possível em espaços onde a cultura ganhou uma dimensão nacional e mundial. Mas sucede que estes engenhos centrais não apagaram a presença das engenhocas tradicionais, que continuaram a persistir até a atualidade.

Por todo o Brasil, desde o Maranhão ao Rio Grande do Sul, persistem ainda testemunhos reais desta tecnologia pré-industrial, cujo testemunho material importa resgatar. O mesmo sucederá em outras regiões do continente americano, como no México, Venezuela e diversas ilhas das Caraíbas, na Índia, China, Camboja e Laos. O caso brasileiro assume uma posição particular no conjunto destas infra-estruturas, pela quantidade de exemplares que teimam em persistir laborando por todo o país.

Uma particularidade da tecnologia pré-industrial está na partilha de processos tecnológicos na transformação de distintos produtos. Com o recurso à força do homem, do vento, do animal ou da água, conseguiu-se movimentar engenhocas capazes de esmagar a azeitona e a cana, moer o cereal e preparar a mandioca. No caso brasileiro, a mandioca conviveu lado a lado com os canaviais, partilhando a tecnologia. Os engenhos em que a engrenagem cumpre uma dupla função são raros, mas fáceis de encontrar nestas circunstâncias. Na Madeira, a força motriz da água era partilhada pela moenda dos cereais e da cana (como no caso do engenho que existiu onde hoje está o Museu Etnográfico da Ribeira Brava), mas no Brasil o mesmo sistema é partilhado pela cana e mandioca (como sucede em Santa Amaro da Imperatriz). Já na Jamaica, a força motriz do vento fazia movimentar uma engrenagem que tinha uma dupla utilização na moenda da cana e do cereal.

O conhecimento da situação só se torna possível mediante um projeto de levantamento exaustivo destas reminiscências pré-industriais, de que o presente projeto pretende ser o primeiro passo.

Temos notícia de alguns projetos que se enquadram neste contexto, mas que não esgotaram ainda a temática ${ }^{6}$. São abordagens circunscritas a uma determinada área ou com um objetivo determinado, que por vezes se alheia da realidade açucareira. Aqui, pretende-se uma abordagem mais abrangente que privilegie as questões tecnológicas.

\section{A Máquina a vapor}

Até o advento do açúcar de beterraba, em princípios do século XIX, a tecnologia de moenda e fabrico do açúcar não sofreu muitas modificações. No tocante à moagem da cana, houve necessidade de compatibilizar as estruturas com a expansão da

\footnotetext{
${ }^{6}$ Temos para o estado de Santa Catarina: PEREIRA, Nereu do Vale, Os Engenhos de Farinha de Mandioca da Ilha de Santa Catarina. Etnografia Catarinense, Florianópolis, 1993. SERPA, Ivan Carlos, Os engenhos de Limeira. História e memória da imigração italiana no vale de Itajaí, ITAJAÍ, 2000; para o estado de Minas Gerais: Marcelo Magalhães Godoy, Dinossauros de Madeira e Ferro Fundido. Os Centenários engenhos de cana de Minas Gerais. Séculos XVII, XIX e XX, in História e Tecnologia do Açúcar, Funchal, 2000, pp.275-300.
} 
área e o volume de cana moída, avançando-se assim, dos ancestrais sistemas para a adaptação dos cilindros. Entre os séculos XV e XVII, as inovações mais significativas ocorrem aqui. Os cilindros passam a dominar todos os sistemas, de tração animal, humana, vento e água, destronando o pilão, o almofariz e a mó. Do simples mecanismo de cilindros duplos horizontais, evolui-se para os verticais, que no século XVII passam a ser triplos, o que permite maior capacidade de moenda e aproveitamento do suco da cana. Com os dois cilindros, poder-se-á aproveitar apenas $20 \%$ do suco da cana, enquanto com três, até $35 \%$. As técnicas experimentadas na moagem vão no sentido e um maior aproveitamento do suco disponível no bagaço da cana. A situação de Cuba, na década de 70 , do século XIX, pode ser elucidativa da realidade ${ }^{7}$.

Uma maior capacidade na moenda implica maior disponibilidade de garapa a ser processada para se poder dispor do melado ou do açúcar. Uma situação empurra à outra, conduzindo à soluções cada vez mais avançadas. As dificuldades com a obtenção de lenhas ou os elevados custos do transporte até ao local do engenho, conduzem à soluções que paulatinamente vão sendo adotadas por todos. Primeiro, reaproveita-se o bagaço da cana e depois, através de um mecanismo de fornalha única, consegue-se alimentar as cinco caldeiras de cozimento. O sistema ficou conhecido por trem jamaicano, por, segundo alguns, ter tido ali origem, mas, na verdade temos informação do seu uso, não tão apurado na Madeira e Canárias, no século XVI. Em 1530, Giulio Landi descreve o sistema de fabrico de açúcar com cinco caldeiras agrupadas:

Os lugares onde com enorme actividade e habilidade se fabrica o açúcar estão em
grandes herdades, e o processo é o seguinte: primeiramente, depois que as canas
cortadas foram levadas para os lugares acima referidos, põem-nas debaixo de
uma mó movida a água, a qual, triturando e esmagando as canas, extrai-lhe todo
o suco. Aqui há cinco vasos postos por ordem, para cada um dos quais o suco
saído das canas passa um certo tempo em ebulição, depois, passando para os
outros casos, com fogo brando, dão-lhe com habilidade a cozedura, de modo que
chegue a espessura tal que, posto depois em formas de barro, possa endurecer. A
espuma que se forma ao cozer o açúcar, deita-se em barricas, exceto a que sai da
primeira cozedura, porque esta se deita fora; mas a outra, que se conserva, é
muito semelhante ao mel"'.

A situação surge também nas Canárias no século XVI. Aqui, as caldeiras reuniam-se em grupos de três ou cinco, sendo servidas por distintas fornalhas ou apenas uma. No engenho de Cristóbal Garcia del Castilho em Telde refere-se que "as fornallas que son todas juntas en el..."

A Jamaica esteve na frente das inovações da tecnologia açucareira a partir da segunda metade do século XVIII. Os ingleses deram o passo definitivo para a mudança radical através da introdução da máquina a vapor. O primeiro engenho horizontal de tipo moderno foi desenhado em 1754 por John Smeaton na Jamaica, recebendo, a partir de 1770 , o impulso da máquina a vapor. A nova tecnologia, que se aperfeiçoou com o andar dos tempos, poderia acoplar até 18 cilindros em sistema de tambor, tornando mais rápida e útil a moenda. Com cinco cilindros, o

\footnotetext{
${ }^{7}$ João José Carneiro da Silva, Estudos Agrícolas, Rio de Janeiro, 1872, p.94.

${ }^{8}$ António Aragão. A Madeira Vista por Estrangeiros.1455-1700, Funchal, 1981, 85-86.

${ }^{9}$ Manuel Lobo, El Ingenio en Canárias, in História e Tecnologia do Açúcar, Funchal, 2000, p.110-112.
} 
aproveitamento do suco podia ir até $90 \%$, enquanto que com os tambores de 18 cilindros, quase se atinge a exaustão com 98\%. Por outro lado, nos engenhos tradicionais, a média de moenda por 24 horas não ultrapassava as 125 toneladas, enquanto que com o novo sistema a vapor, começou-se a atingir mais de três mil toneladas de cana.

Segue-se o processo de fabrico do açúcar, que se distribui por quatro momentos: purificação da garapa, evaporação da água e, finalmente, a clarificação e cristalização. Até os inícios do século XIX, o processo poderia durar de 50 a 60 dias, mas as aportações tecnológicas conduziram a que se passasse a fazer em apenas um mês, em 1830, e em apenas 16 horas, em 1860, através do novo sistema de centrifugação. As primeiras mudanças ocorrem no processo de clarificação. Em 1805, Guillon, refinador do açúcar em New Orleans, preconiza o uso do carvão para purga xarope; em 1812, Edward Charles Howard constrói a primeira caldeira de vacuum, conhecida como "howard saccharine evaporator", que veio revolucionar o sistema de fabrico do açúcar. Três anos depois surge em Inglaterra o sistema de filtros de Taylor. O evaporador de múltiplo efeito foi inventado em 1830 por Norbert Rillius [1806-1894], de New Orleans, sendo usado nos primeiros engenhos desde 1834. Desse modo, torna-se mais fácil a retirada de cerca de $85 \%$ de água que existe no suco da cana e um maior aproveitamento do açúcar. As novidades na clarificação e cristalização ocorrem num segundo momento. Assim, em 1844, o alemão Schottler aplicou pela primeira vez a força centrífuga na separação do melaço do açúcar branco, mas foi Soyrig quem construiu, em 1849, a primeira máquina de centrifugação, que abriu o caminho para o fabrico do primeiro açúcar granulado, em 1859. Esse sistema vinha sendo utilizado desde 1843 na indústria têxtil. Os equipamentos contribuíram para acelerar o processo de purga do açúcar, permitindo que se passasse do moroso processo de quase dois meses para apenas 16 horas, e hoje em apenas alguns segundos.

Outro fator significativo da safra referia-se à velocidade a que o processo da moenda da cana deveria ocorrer, mais uma vez no sentido de se retirar o maior rendimento da cana através da sacarose. A cana tem um momento ideal para ser moída e, depois de cortada, os prazos para a moenda são curtos, caso se queira evitar a fermentação, que é sinônimo de perda de sacarose ${ }^{10}$. Nos avanços tecnológicos, tem-se em conta essa corrida contra o tempo, criando-se mecanismos capazes de moer cana como maior rapidez ${ }^{11}$.

No contexto da política protecionista, merece lugar de relevo o debate em torno da "questão Hinton", que animou o meio político entre finais do século XIX e princípios do seguinte. Foi sem dúvida o problema que mais apaixonou a opinião pública, nas vésperas e durante a República. Publicaram-se inúmeros folhetos, os jornais encheram-se de opiniões contra e a favor. O momento mais importante foi a polêmica que, em 1910, se ateou no Parlamento. Cesário Nunes documenta a situação de forma lapidar: "Em Portugal nenhuma questão econômica atingiu tão alta preponderância e trouxe e tão grandes embaraços legislativos às entidades governativas como o problema sacarino da Madeira."

\footnotetext{
${ }^{10} \mathrm{Cf}$. J. de Laguarrique d eSurvilliers, Manuel de Sucrerie de Cannes, Paris, 1932, pp. 29.

${ }^{11}$ Cf. Nilo Cairo, O Livro da Canna de Assucar, Curitiba, 1924, pp. 85-86, 109; A.Bernard, A Evolução das Moendas de Canas, Brasil Açucareiro, XXXVIII, 2, 1951, pp. 73, 76.
} 
No contexto da política protecionista, merece lugar de relevo o debate em torno da "questão Hinton", que animou o meio político entre finais do século XIX e princípios do seguinte. Foi sem dúvida o problema que mais apaixonou a opinião pública, nas vésperas e durante a República. Publicaram-se inúmeros folhetos, os jornais encheram-se de opiniões contra e a favor ${ }^{12}$. O momento mais importante foi a polêmica que, em 1910, se ateou no Parlamento. Cesário Nunes ${ }^{13}$ documenta a situação de forma lapidar: "Em Portugal nenhuma questão econômica atingiu tão alta preponderância e trouxe e tão grandes embaraços legislativos às entidades governativas como o problema sacarino da Madeira".

Tudo começou em 23 de Março de 1879 com a inauguração da Companhia Fabril do Açúcar Madeirense. Era uma fábrica de destilação de aguardente e de fabrico de açúcar sita à Ribeira de $\mathrm{S}$. João. Demarcou-se das demais com o recurso da tecnologia francesa, usufruindo dos inventos patenteados em 1875 pelo Visconde de Canavial. O cônego Feliciano João Teixeira ${ }^{14}$, sócio do empreendimento, no discurso de inauguração afirma ser esse um "grandioso monumento, que abre uma época verdadeiramente nova e grande na história da indústria fabril madeirense". Isto foi apenas o princípio de um conflito industrial, onde imperou a lei do mais forte. Tal como o afirmava em 1879, no momento encerramento, José Marciliano da Silveira ${ }^{15}$ "a fábrica de são João foi cimentada com o veneno da maldade; era o seu fim dar cabo de todas as que existiam..." e acabou por cavar o fosso da ruína.

A polémica ateou-se com o plágio, por parte da família Hinton, da invenção do Visconde Canavial ${ }^{16}$, que havia patenteado em 1870 um invento que consistia em lançar água sobre o bagaço, o que propiciava maior aproveitamento do suco da cana. Constava da patente o uso exclusivo pela fábrica de $\mathrm{S}$. João, mas o engenho de Hinton cedo se apressou a copiar o sistema. Com isso, o lesado moveu, em 1884, uma ação civil contra o contrafactor. A família Hinton ficou para a história como a autora da inovação ${ }^{17}$, que como sabemos, foi comum em vários espaços açucareiros. Em 1902, a fábrica Hinton experimentou um novo sistema em ligação com M. León Naudet que ficou conhecido como sistema Hinton-Naudet, que consistia em submeter o bagaço a uma circulação forçada num aparelho de difusão, conseguindo-se um ganho de mais $17 \%$ e maior pureza da garapa, evitando as defecadoras ${ }^{18}$. Essa intervenção pioneira é sublinhada por inúmeras bibliografias da especialidade $^{19}$.

O engenheiro M. Naudet esteve no Torreão nos dias 21 e 22 de Junho de 1907 combinando com João Higino Ferraz a forma de montagem do sistema de difusão, o triple e o "freitag"(cuite). Todavia, a instalação do novo maquinismo começou apenas

\footnotetext{
${ }^{12}$ A Leitura dos Jornais da época assim o evidencia. Veja-se por exemplo Francisco Canais Rocha, Perfeito de Carvalho contra o monopólio Hinton, História, n.144, 1991, pp.49-61; Emanuel Janes, in História do açúcar. Rotas e Mercados, Funchal, 2002, pp.

${ }_{13}^{13}$ Politica sacarina, Funchal, 1940

${ }^{14}$ Discurso pronunciado pelo conego Feliciano João Teixeira Presidente da Assembleia Geral da C $C^{a}$ Fabril de Assucar Madeirense no dia da inauguração do estabelecimento, 23 de Março de 1873, Funchal, 1873.

${ }^{15} \mathrm{~A}$ companhia fabril de assucar madeirense os seus credores o Athleta e o sr. Dr. João da Câmara Leme, Funchal, 1879.

${ }^{16}$ Uma acção civil contra o sr. W. Hinton fabricante de assucar e aguardente na cidade do Funchal (Ilha da Madeira)..., Funchal, 1884.

${ }^{17}$ W. Koebel, Madeira. Old and New, Londres, 1909, p.129; Eduardo Pereira, Ilhas de Zargo, vol. I (Funchal, 1989), pp.541542.

${ }^{18}$ Eduardo Pereira, Illhas de Zargo, vol. I (Funchal, 1989), pp.541-542

${ }^{19}$ Cf. International SugarJournal, 1905; H. C. Prisen Guerligs, Cana Sugar and its Manufacture, Londres, 1909, pp. 115, 117
} 
em meados de setembro, após a conclusão da safra. Até 1909 o técnico do Hinton manteve correspondência assídua no sentido de esclarecer pormenores sobre a instalação dos mecanismos. Na seqüência, João Higino Ferraz se deslocou a Paris para novo encontro com Naudet e visita às fábricas de açúcar de beterraba ${ }^{20}$.

A segunda metade do século XIX foi o momento da aposta definitiva na engenharia açucareira, contribuindo para importantes inovações. O mercado ocidental foi inundado de açúcar de cana e beterraba. O desenvolvimento da indústria de construção de equipamentos para o fabrico de açúcar, seja de cana ou de beterraba, aconteceu em países onde esta assumia uma posição significativa na economia. Deste modo, a França e a Inglaterra assumiram a posição pioneira no desenvolvimento da tecnologia. Os Franceses detinham importantes colônias açucareiras nas Antilhas, enquanto os alemães apostavam forte em Java. Os ingleses surgem por força da colônia nas Antilhas e Índia, e os Estados Unidos da América, com New Orleans e depois o Havai. Cuba foi um dos espaços açucareiros onde mais se inovou em termos tecnológicos. As primeiras décadas do século XIX foram de plena afirmação da ilha, que se transformou em modelo para a indústria açucareira.

Em França tudo começou com o químico Charles Derosne (1779-1846), que montou em 1812 uma fábrica de construção de aparelhos de destilação continua. Nesta empresa, passou a trabalhar, em 1824, J. F. Cail, na qualidade de operário de carvão e, em 4 de Março de 1836, passa à condição de associado. A sociedade Derosne et Cail se manteve até 1850 , altura em que passou a chamar-se J. F. Cail et Cie, que em 1861 passou a cooperar com a nova Cie Fives-Lille, especializada no fabrico de equipamentos para fábricas de açúcar e estradas de ferro. Os equipamentos, saídos da empresa Cail, chegaram às colônias holandesas, espanholas, inglesas e francesas, México, Rússia, Áustria, Holanda, Bélgica e Egito. À indústria francesa, juntaram-se outros complexos industriais na Europa: Inglaterra (Glasgow, Birmingham, Nottingham, London, Manchester, Derby), Holanda (Breda, Roterdão, Schiedam, Ultrecht, Delft, Hengelo, Amsterdam), Estados Unidos da América (Oil City, Ohio, Denver, New Jersey), Alemanha (Magdeburgo, Zweibruecken, Halle, Dusseldorf, Sangerhausen, Ratingen, Halle), Bélgica (Bruxelas, Tirlemont).

A Inglaterra foi, desde meados do século XVII, um dos mais importantes centros de refinação de açúcar na Europa. As refinarias proliferam nas cidades de nas cidades de Bristol, Essex, Greenock, Lancaster, Liverpool e Southampton ${ }^{21}$. Isso justifica o desenvolvimento tecnológico. Aqui merece destaque a iniciativa de Mirless Watson. A abertura às inovações tecnológicas como forma de tornar concorrencial o produto, acarreta algumas conseqüências para a indústria no âmbito nacional. Os investimentos são vultuosos e, por isso mesmo, só se tornam possíveis mediante incentivos do Estado. A inovação e recuperação da capacidade concorrencial só se tornaram possível à custa da concentração. Tanto em Cuba como no Brasil, a década de oitenta foi marcada pelos grandes engenhos centrais.

\footnotetext{
${ }^{20}$ Arquivo de João Higino Ferraz, copiador de cartas 1905-1913, fls.53, 65-78.

${ }^{21}$ John M. Hutcheson, notes on the Sugar Industry of the United Kingdom, Greenock, 1901; Frank Lewis, Essex and sugar, 1976.
} 


\section{Conclusão}

A Madeira marcou um passo decisivo na História da Cana-de-açúcar entre os séculos XV e XX. Todavia, ao contrário do que sucede com o vinho, a cultura não se manteve como uma constante da história da ilha, notando-se um hiato no século XVIII. O vinho, que a partir de meados do século XVI havia retirado espaço à cana sacarina, estava agora, em meados da centúria oitocentista, a ser dominado pelo retorno dos canaviais. A cultura se expandiu a Norte e a Sul, tornando-se um dos fatores mais importantes de animação da agricultura e da indústria.

Em qualquer dos momentos a Madeira esteve na linha da frente das inovações tecnológicas. Nos séculos XV e XVI acresce a função de distribuição da cultura e técnica em todo o espaço atlântico. Para finais do século XIX e princípios do seguinte, ficaria reservado papel pioneiro no ensaio de algumas técnicas e sistemas de fabrico de açúcar e aguardente que revolucionaram todo o processo industrial. Para isso, foi importante a ação de João Higino Ferraz, que na qualidade de gerente técnico, conseguiu manter contatos estreitos com os ensaios feitos em França, do qual o sistema de Naudet é exemplo. Foi na ilha que se ensaiaram de novo alguns processos tecnológicos e químicos, que depois adquiriram um papel de relevo no processo de industrialização do fabrico de açúcar e aguardente.

\section{Anexos}

Canaviais e Açúcar: uma tradição milenar ${ }^{22}$

Os Quadros 1 a 6 apresentam uma cronologia do açúcar de cana e de beterraba, bem como da evolução da tecnologia do açúcar e algumas curiosidades sobre o tema.

\footnotetext{
${ }^{22}$ VIEIRA, Alberto. Centro de Estudos de História do Atlântico. Funchal [Madeira], Portugal. <avieira@avieira.net> $<$ http://www.avieira.net>
} 
Quadro 1. Cronologia da expansão da cana-de-açúcar. Fonte: VIEIRA, Alberto. <http://www.avieira.net>. Adaptado pelo Editor da Revista Labor \& Engenho para publicação nesta edição.

\begin{tabular}{|c|c|}
\hline \multicolumn{2}{|r|}{ Expansão da cana-de-açúcar } \\
\hline $9000-8000 \mathrm{AC}$ & Domesticação da cana na Papua Nova Guiné \\
\hline $8000 \mathrm{AC}$ & Introdução em Bengala \\
\hline $6000 \mathrm{AC}$ & Descoberta da Sacharum Robustum na Ásia \\
\hline $3000 \mathrm{AC}$ & Domesticação do sorghum na Etiópia \\
\hline $2500 \mathrm{AC}$ & Papua Nova Guiné Saccharum officinarum \\
\hline $2000 \mathrm{AC}$ & A cultura da cana sacarina faz de forma intensiva na Índia \\
\hline $1500 \mathrm{AC}$ & Expansão da cultura na Polinésia e Melanésia \\
\hline $1000 \mathrm{AC}$ & Índia, saccharum berberi \\
\hline $700 \mathrm{AC}$ & Difusão da Saccharum officinarum na Ásia \\
\hline $600 \mathrm{AC}$ & Introdução da cana nas ilhas do Hawaii, por emigrantes do Pacífico sul \\
\hline $510 \mathrm{AC}$ & Descoberta da cana pelos Persas \\
\hline $375 \mathrm{AC}$ & Primeira referência ao açúcar branco \\
\hline $325 \mathrm{AC}$ & $\begin{array}{l}\text { O general macedónio Nearchus da campanha de Alexandre o Grande na Ásia } \\
\text { refere o açúcar de cana }\end{array}$ \\
\hline $300 \mathrm{AC}$ & A cana é usada na alimentação na Índia \\
\hline $200 \mathrm{AC}$ & Cultivo da cana no Sul da China \\
\hline $600 \mathrm{DC}$ & $\begin{array}{l}\text { As árabes descobrem o açúcar na Pérsia e iniciam a sua divulgação no } \\
\text { Mediterrâneo: 640, Síria; 644, Chipre; 655, Sicília; 682, Marrocos; } 700 \text {, Palestina; } \\
\text { 710, Egipto; 714, Al-Andalous; 823, Creta; 870, Malta. }\end{array}$ \\
\hline 1000 & O açúcar é uma das mercadorias mais importantes do comércio do Mediterrâneo \\
\hline 1285 & Marco Pólo refere o fabrico de açúcar na China, Índia e África Oriental. \\
\hline 1305 & Primeira referência à cana-de-açúcar em Valencia \\
\hline 1319 & Primeira referência à importação de açúcar em Inglaterra \\
\hline 1425 & $\begin{array}{l}\text { Expansão da cana-de-açúcar ao Atlântico, a partir da Madeira: 1474: Açores; } \\
\text { 1483, Canárias; } 1484, \text { S. Tomé; } 1498 \text {, Cabo Verde }\end{array}$ \\
\hline 1456 & Primeira referência ao açúcar da Madeira em Bristol \\
\hline 1483 & $\begin{array}{l}\text { O governador de Gran Canaria D. Pedro de Vera manda buscar à Madeira canas } \\
\text { e mestres para a introdução cultura em Gran Canaria e La Palma }\end{array}$ \\
\hline 1484 & Primeira experiência da cultura da cana-de-açúcar em S. Tomé \\
\hline 1485 & $\begin{array}{l}\text { A coroa recomenda a Afonso da Paiva a cultura de canaviais em S. Tomé com } \\
\text { gentes da Madeira. }\end{array}$ \\
\hline 1509 & Primeiras plantações de cana-de-açúcar no Brasil \\
\hline 1640 & Início do cultivo da cana-de-açúcar em Barbados \\
\hline 1651 & Primeira plantação de cana-de-açúcar em Suriname por Lord Willoughby \\
\hline 1751 & Introdução da cana-de-açúcar em Louisiana \\
\hline 1765 & Início da cultura da cana-de-açúcar em St Lúcia \\
\hline
\end{tabular}



quem iniciou a indústria

1890

Criação em Java e Barbados de Estações agronómicas para selecção das diversas variedades de cana-de-açúcar

Quadro 2. Cronologia da Tecnologia da cana-de-açúcar e beterraba. Fonte: VIEIRA, Alberto. <http://www.avieira.net>. Adaptado pelo Editor da Revista Labor \& Engenho para publicação nesta edição.

\section{Tecnologia da cana-de-açúcar e beterraba}

\begin{tabular}{|c|c|}
\hline $3600 \mathrm{AC}$ & Primeira referência ao sistema de destilação, usado na perfumaria. \\
\hline $500 \mathrm{AC}$ & Fabrico de açúcar na Índia \\
\hline $375 \mathrm{AC}$ & Primeira referência ao açúcar branco \\
\hline $325 \mathrm{AC}$ & $\begin{array}{l}\text { O general macedónio Nearchus da campanha de Alexandre o Grande na Ásia } \\
\text { refere o açúcar de cana }\end{array}$ \\
\hline 1285 & Marco Pólo refere o fabrico de açúcar na China, Índia e África Oriental \\
\hline 1470 & Estabelecimento de refinarias em Veneza, Antuérpia e Bolonha \\
\hline 1483 & $\begin{array}{l}\text { O governador de Gran Canaria D. Pedro de Vera manda buscar à Madeira canas } \\
\text { e mestres para a introdução cultura em Gran Canaria e La Palma }\end{array}$ \\
\hline 1485 & $\begin{array}{l}\text { A coroa recomenda a Afonso da Paiva a cultura de canaviais em S. Tomé com } \\
\text { gentes da Madeira }\end{array}$ \\
\hline 1515 & Construção no Brasil(S. Vicente) do primeiro engenho régio \\
\hline 1518 & $\begin{array}{l}\text { Gonçalo Eanes Velosa, apontado por alguns como madeirense, constroi o } \\
\text { primeiro engenho em La Hispaniola }\end{array}$ \\
\hline 1532 & $\begin{array}{l}\text { Martim Afonso de Sousa leva cana e mestres de engenho da Madeira para S. } \\
\text { Vicente (Brasil) }\end{array}$ \\
\hline 1533 & $\begin{array}{l}\text { Fundação do engenho do Governador em S. Vicente, o primeiro construído no } \\
\text { Brasil }\end{array}$ \\
\hline 1537 & $\begin{array}{l}\text { Os carpinteiros, construtores de engenhos da ilha da Madeira, estão proibidos a } \\
\text { emigrar para Marrocos }\end{array}$ \\
\hline 1640 & Início do cultivo da cana-de-açúcar em Barbados \\
\hline 1651 & Primeira plantação de cana-de-açúcar em Suriname por Lord Willoughby \\
\hline 1700 & Invenção do trem jamaicano \\
\hline 1768 & Primeira máquina a vapor na Jamaica \\
\hline 1780 & Cuba adopta o trem francês \\
\hline 1791 & $\begin{array}{l}\text { O químico russo, Lowitz, demonstra as propriedades depurativas do carvão, que } \\
\text { passará a ser usado na purga do açúcar. O engenheiro Estebam La Faye fabrica a } \\
\text { primeira moenda a vapor em Cuba }\end{array}$ \\
\hline 1798 & Utilização de caldeiras clarificadoras para eliminar as impurezas \\
\hline 1794 & $\begin{array}{l}\text { John Collinge apresenta inovação do engenho horizontal de três cilindros. Início } \\
\text { da fabricação em série da moenda a vapor, na Inglaterra }\end{array}$ \\
\hline 1805 & $\begin{array}{l}\text { Guillon, refinador do açúcar em Orleans preconiza o uso do carvão para purga } \\
\text { charope }\end{array}$ \\
\hline 1812 & Edward Charles Howard constrói a primeira caldeira de vacuum, patenteado no \\
\hline
\end{tabular}


ano seguinte este método de evaporação. O químico Charles Derosne cria a primeira fábrica de açúcar a carvão em Cahillot

$1815 \quad$ Em Inglaterra, Taylor estabelecem um sistema de filtros. Primeira máquina a vapor no Brasil, de Watt \& Boulton

$1820 \quad$ Afirmação da máquina a vapor de Fawcett

1829 Construção da primeira caldeira a vapor no Brasil, pela Fundição Aurora

1830 Norbert Rillius de N. Orleans descobriu a caldeira de vacuum, surgindo os primeiros engenhos desde 1845

1833 Início do uso da máquina a vapor na refinação do açúcar em Cuba

1837 Inglês Penzoldt constrói o primeiro aparelho de centrifugação, que em 1843 passou a ser usada na purga do açúcar

1843 Norbert Rillieux [1806-1894] introduz na Louisiana o sistema de evaporação de múltiplo efeito

1844 O alemão Schottler aplicou pela primeira vez a força centrífuga na separação do melaço do açúcar branco

1849 Início do uso da turbina na indústria açucareiraConstrução da primeira máquina de centrifugação por Soyrig

1855 Utilização da máquina de vacuum na cristalização do açúcar

1859 Primeira fabricação de açúcar branco granulado

1860 Primeira máquina de centrifugação para purificar o açúcar

1861

Fundação da Companhia Fives-Lille, especializada no fabrico de equipamentos para as fábricas de açúcar

1865 Taylor e Martineau constroem na Inglaterra um aparelho onde a evaporação se fazia com a ajuda do vapor de água a alta pressão, passando as serpentinas no meio do xarope

1870 Instalação da primeira caldeira de vacuum em Pernambuco

1871 Théophile Rousselot, engenheiro na Martinica estabelece o mecanismo do engenho de três cilindros

1879 Constantine Fahlberg regista a patente da sacarina

1890 O pão de açúcar cede definitivamente o lugar ao açúcar granulado

$1937 \quad$ Michael Sveda descobre a cyclamate

$1965 \quad$ James Shlatter Descobre o aspartame

1979 Atinge-se o estado adulto da produção de açúcar, conseguindo-se extrair cerca de $85 \%$ da garapa do bagaço 
Quadro 3. Curiosidades sobre o açúcar da cana-de-açúcar e da beterraba. Fonte: VIEIRA, Alberto. <http://www.avieira.net>. Adaptado pelo Editor da Revista Labor \& Engenho para publicação nesta edição.

\begin{tabular}{|c|c|c|}
\hline \multicolumn{3}{|c|}{ Curiosidades } \\
\hline Lenhas e Deflorestação & \multicolumn{2}{|c|}{$\begin{array}{l}\text { Século XVIII no Brasil } 1 \mathrm{~kg} \text { de açúcar equivale a cerca de } 15 \mathrm{~kg} \\
\text { de lenha. Cada hectare equivale a } 200 \text { toneladas de lenha }\end{array}$} \\
\hline \multirow{8}{*}{ Beterraba } & 1575 & $\begin{array}{l}\text { François Olivier de Serres (1539-1619) em "Theatre } \\
\text { dell'Agriculture", refere que se pode extrair açúcar da } \\
\text { beterraba }\end{array}$ \\
\hline & 1745 & $\begin{array}{l}\text { Frederico O Grande da Prússia ordena aos químicos } \\
\text { que investiguem a forma de retirar sacarose de frutos }\end{array}$ \\
\hline & 1747 & $\begin{array}{l}\text { O Barão Andraeas Sigismond Marggraf [1709-1782], da } \\
\text { Academia de Ciências de Berlim, confirma que o açúcar } \\
\text { existente na Beterraba é igual ao da cana sacarina }\end{array}$ \\
\hline & 1786 & $\begin{array}{l}\text { Carl Franz Achard fez um estudo sistemático sobre a } \\
\text { beterraba e montou a primeira fábrica de açúcar de } \\
\text { beterraba }\end{array}$ \\
\hline & 1799 & $\begin{array}{l}\text { Franz Carl Achard anuncia a obtenção de açúcar em } \\
\text { larga escala, construindo uma fábrica na Silésia. } \\
\text { Presenteou Frederico III da Prússia com um pão de } \\
\text { açúcar de beterraba }\end{array}$ \\
\hline & 1812 & $\begin{array}{l}\text { Construção da primeira fábrica para açúcar de beterraba } \\
\text { em França }\end{array}$ \\
\hline & 1866 & $\begin{array}{l}\text { Jules Robert desenvolveu o processo de difusão para } \\
\text { extrair o açúcar da beterraba }\end{array}$ \\
\hline & 1880 & $\begin{array}{l}\text { A beterraba conduz a inovações na indústria química, } \\
\text { enquanto o seu açúcar, suplanta o da cana e conduz ao } \\
\text { colapso do mercado }\end{array}$ \\
\hline \multirow{2}{*}{ Tecnologia e produção de açúcar } & 1800 & $\begin{array}{l}\text { A purga durava entre } 50 \text { a } 60 \text { dias, passando para } 40 \\
\text { dias em } 1820 \text { e } 24 \text { a } 32 \text { dias em } 1830\end{array}$ \\
\hline & 1860 & $\begin{array}{l}\text { A máquina de centrifugação reduz o processo de } \\
\text { refinação do açúcar de } 3 \text { semanas para } 16 \text { horas }\end{array}$ \\
\hline
\end{tabular}


Quadro 4. Tecnologia do açúcar: tradicional vs industrial (séc. XIX). Fonte: VIEIRA, Alberto. <http://www.avieira.net>. Adaptado pelo Editor da Revista Labor \& Engenho para publicação nesta edição.

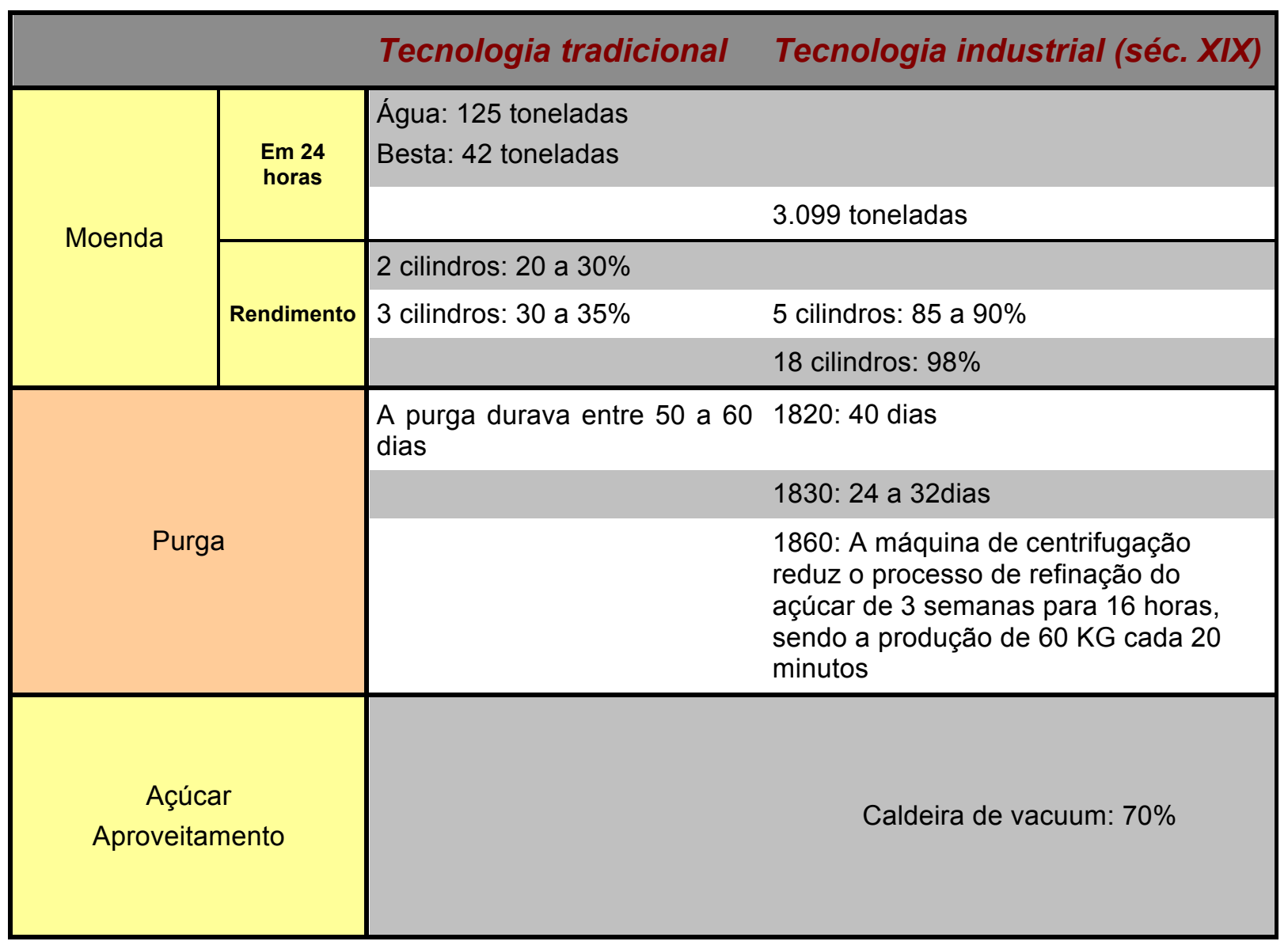


Quadro 5. Aproveitameto da garapa. Fonte: VIEIRA, Alberto. <http://www.avieira.net>. Adaptado pelo Editor da Revista Labor \& Engenho para publicação nesta edição.

$$
\begin{aligned}
& 2 \text { cilindros }=20 \% \text { de aproveitamento da garapa disponível na cana } \\
& 3 \text { cilindros }=35 \% \text { de aproveitamento da garapa disponível na cana } \\
& 5 \text { cilindros }=90 \% \\
& 18 \text { cilindros }=98 \%
\end{aligned}
$$

Quadro 6. Curiosidades sobre o processo de fabrico de açúcar. Fonte: VIEIRA, Alberto. <http://www.avieira.net>. Adaptado pelo Editor da Revista Labor \& Engenho para publicação nesta edição.

$$
\begin{aligned}
& \text { Trem Jamaicano: poupança de } 10 \text { kg lenhas em cada kg de açúcar } \\
& \text { Processo de fabrico de açúcar (séculos XV-XVIII): } 50 \text { até 60dias } \\
& \text { Processo de fabrico de açúcar em 1830: } 1 \text { mês } \\
& \text { Processo de fabrico de açúcar em 1860: } 16 \text { horas (centrifugação) }
\end{aligned}
$$

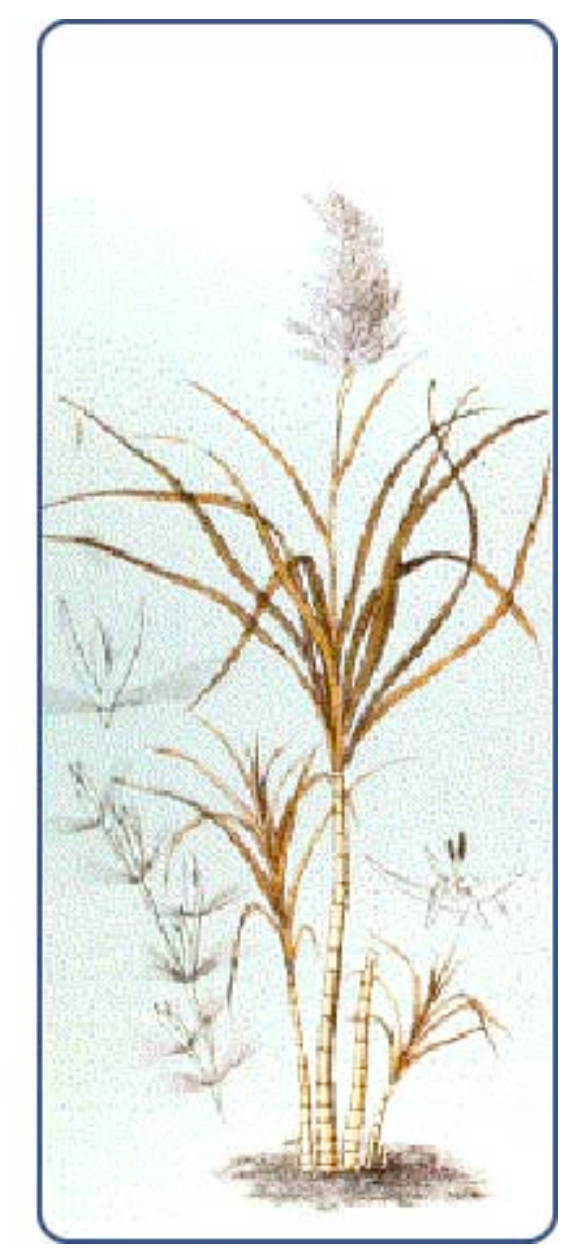

Figura 1. llustração de cana-de-açúcar. Fonte: VIEIRA, Alberto. <http://www.avieira.net>. Adaptado pelo Editor da Revista Labor \& Engenho para publicação nesta edição. 


\section{Referências}

ARNOLD, David. The Problem of Nature: Environment, Culture and European Expansion (new perspectives on the past). Oxford, 1996.

AZNAR VALLEJO, Eduardo. La integración de las islas Canarias en la Corona de Castilla 14781526. La Laguna, 1983, Las Palmas, 1994.

BLUME, Helmut. Geography of sugar cane. Environmental, structural and economical aspects of cane sugar production. Berlim, 1920.

BOTELHO, Teresa Maria B. Tecnologia popular e energia no sector residencial rural. Um estudo sobre o fogão a lenha. Rio de Janeiro, 1986.

CAMACHO y PÉREZ GALDÓS, G. El cultivo de la cana de azúcar y la industria azucarera en Gran Canaria (1510-1535) in Anuario de Estudios Atlanticos. $n^{\circ} 7,1961$.

CIORANESCU, A. Thomas Nichols, mercader de azúcar, hispanista y hereje. La Laguna, 1963.

CROSBY, Alfred W. Ecological imperialism: the biological expansion of Europe 900-1900. Cambridge, 1986 (edição em Português, S. Paulo, 1993).

The Columbian exchange. Biological and cultural consequences of 1492. Westport, 1973.

DEAN, Warren. A ferro e fogo. A história e a devastação de mata atlântica brasileira. S. Paulo, 1996.

DEER, Noel. History of sugar. 2 vol. London, 1949.

DÍAZ PADILLA, Glória e RODRIGUEZ YANESA, José Miguel. El senorio en Las Canarias

Occidentales. La Gomera y el Hierro hasta 1700. Santa Cruz de Tenerife, 1990.

FERNÁNDEZ-ARMESTO, Felipe. The Canary Islands after the conquest. Oxford, 1982.

FERRÃO, J. E. A influencia portuguesa na expansão das plantas no Mundo. Lisboa, 1980.

A aventura das plantas e os descobrimentos portugueses. Lisboa, 1992. 1986.

Transplantação de Plantas de Continentes para Continentes no Século XVI. Lisboa,

A Difusão das Plantas no Mundo através dos Descobrimentos in Mare Liberum. $\mathrm{n}^{\circ}$ 1, 1990. p.131-142.

FREIRE, Gilberto. Nordeste. Rio de Janeiro, 1985.

GALlOWAY, J. H. The Sugar Cane Industry. A Historical Geography from its origins to 1914. Cambridge, 1990. 
GODINHO, Vitorino Magalhaes. O açúcar dos arquipélagos atlanticos, in Os Descobrimentos e a Economia Mundial. vol. IV, Lisboa. p. 69-93.

Gouveia, David Ferreira de. A Manufactura Açucareira Madeirense (1420-1550). Influência Madeirense na Expansão e Transmissão da Tecnologia Açucareira, in Atlântico, Funchal. 1987, $\mathrm{n}^{\circ} .10$.

O açúcar da Madeira. A manufactura açucareira madeirense (1420-1550), Atlântico, n. ${ }^{4}$, 1985, p. 260-272.

A manufactura açucareira madeirense (1420-1450). Influencia madeirense na expansão e transmissão da tecnologia açucareira, in Atlântico. n. ${ }^{\circ} 10,1987$, p. 115-131.

O açúcar e a economia madeirense (1420-1550). Produção e acumulação in Atlântico. n. ${ }^{\circ}$ 16, 1988, p.262-283

O açúcar e a economia madeirense (1420-1550). Consumo de excedentes, Islenha, n. ${ }^{\circ} 8$ (1991), pp. 11-22.

Gente d'engenho in Islenha. $\mathrm{n}^{\circ} .13,1993,81-95$.

. Açúcar confeitado na Madeira in Islenha. $n^{\circ} .11,1992$, p. 35-52.

GREENFIELD, Sidney M. Madeira and the beginings of sugar cane cultivation and plantation slavery in Comparative Perspectives on New World Plantation Societies. New York Annals of the New York Academy of Sciences. vol. 292. New York, 1977. p. 236-252.

GROVE, Richard. Green imperialism. Colonial expansion, tropical islands Edens, and the origins of environmentalism, 1600-1860. Cambridge, 1995.

HENRIQUES, Isabel Castro. O Ciclo do açúcar em S. Tomé nos séculos XV e XVI in Albuquerque, Luís de (dir.). Portugal no Mundo. Lisboa, sd, vol. I, p.264-280.

LAPUS, G. Les Produits Coloniaux d'Origine Végétale. Paris, 1930.

LOBO, Manuel. El ingenio en Canárias in História e Tecnologia do Açúcar. Funchal, 2000. p.105117.

. La técnica de cultivo de la caria de azúcar in Islenha. n8(|99I), p.5-I0.

LUISA FABRELLAS, Maria. La producción de azúcar en Tenerife in Revista de História. $n^{\circ} 100$, 1952, p. 454-475.

MACKENZIE, J. (ed.). Imperialism and their natural world. Manchester, 1990.

MALPICA, Antonio. El azúcar en el Encuentro entre dos Mundos. Barcelona, 1992.

Médio Físico y Territorio: el Ejemplo de la Caña de Azúcar a finales de la Edad Media. Actas del Quinto Seminario de la Caña de Azúcar. Paisajes del Azúcar. Granada, 1995, 11-40.

El Médio Físico y sus Transformaciones a Causa del Cultivo de la Caña de Azúcar en época Medieval. El Caso de la costa de Granada in História e Tecnología do Açúcar. Funchal, 2000, 87104. 
MELVILLE, Elinor. A plague of sheep environmental consequences of the History of Mexico. Cambridge, 1994.

MINTZ, Sidney W. Sweetness and Power. New York, 1985.

MORREALE, Antonino. Lo Zuccherificio e l'impatto sull'ambiente in Sicília tra XV e XVII secolo, in História e Meio-ambiente o Impacto da Expansão Europeia. Funchal, 1999, 159-180.

NARANJO CIGALLA, Agustín, Octavio Rodriguez Delgado, Marcos Salas Pascual. Características Bioclimáticas del Território Antiguamente Cultivado de Caña de Azúcar en las Islas Canarias in $\mathbf{0}$ Açúcar e o Quotidiano. CEHA: Funchal, 2004. 271-302.

[Octavio Rodriguez Delgado, Marcos Salas Pascual, Maria Teresa Cáceres Lorenzo]-Evolución y Aprovechamientos de la Vegetación Canaria, Derivados del Cultivo de la Caña de Azúcar, in O Açúcar e o Quotidiano. CEHA: Funchal, 2004.283-302.

NEEDHAM, Joseph. Science of Civilization in China. vol. VI/3, (C. Daniels and N. K. Menzies), London, 1996.

NOVAK, Barbara. Nature and Culture-american Landscape Painting. 1825-1875. N. Y., 1980.

Paisages del azucar. Actas del Quinto Seminario Internacional. Motril, 1995.

OSBORNE, Michael. Nature, the exotic and the Science of French Colonialism. Bloomington, 1994.

PARREIRA, H. G. de Amorim. Historia do Açúcar em Portugal in Anais da Junta de Investigação do Ultramar. Vol. VI, tomo I, 1952.

PEREZ AGUADO, Luis. La Caña de Azúcar en el Desarollo de la Ciudad de Telde (siglo XVI). Las Palmas, 1982.

PREST, J. The Garden of Eden: The Botanic Garden and the Re-creation of Paradise. New Haven, 1981; PYNE, S. J., Fire in America, 1982.

RAU, Virginia e MACEDO, Jorge. O Açúcar na Madeira no Século XV. Funchal, 1992.

RAU, Virgínia. O Açúcar de S. Tomé no Segundo Quartel do Século XVI. Lisboa, 1971.

RIVERO SUÁREZ, Benedicta. El azúcar en Tenerife (1496-15509). La laguna, 1990.

SANTANA, SANTANA, A. Evolución del Paisaje de Gran Canaria (Siglos XV-XIX). Las Palmas de Gran Canaria, 2001.

SANTANA GODOY, J. R., "Acerca de un recuento decimal de los azúcares de las islas confeccionado por Millares Torres (1634-1813" in A. Millares Torres, Historia General de las islas Canarias, T. IV, Las Palmas, 1979, pp. 151-155.

SARMENTO, Alberto Artur.História do Açúcar na Ilha da Madeira. Funchal, 1945.

THIRGOOD, J. V. Man and the Mediterranean Forest. A History of resource depletion. London, 1981.

THOMAS, K. Man and the Natural World. Changing Attitudes in England. 1500-1800. Oxford, 1983. 
VIEIRA, Alberto. A Rota do Açúcar na Madeira. Funchal, 1996.

Do Éden à Arca de Noé. Funchal, 1999.

Canaviais, Engenhos, Açúcar e Aguardente na Madeira. Séculos XV- XX. Funchal, 2004.

VINA BRITO, Ana; PÉREZ MORERA, Jesús; MACHADO PRILLA, José Luís. La cultura del azúcar. Los ingenios de Argual y Tazacorte. La Palma, 1994.

WATTS, D. Environmental Change. Slavery and Agricultural Development in the Caribbean since 1492. Cambridge, 1985 (com edição em castelhano em 1992).

WHEATLEY, Helen. Agriculture, Resource Explotation and Environmental Chang. 1997.

WHITE, Richard. Land Use, Environment and Social Change. Seattle, 1980.

WORSTER, D. Nature's Economy: A History of Western Ecological Ideas. Cambridge, 1985. 